\title{
ESTADO DE LA CUESTIÓN SOBRE LA VIVIENDA URBANA ROMANA EN EL ÁREA VALENCIANA
}

En el siguiente artículo pretendemos realizar un estado de la cuestión del conjunto de hallazgos arqueológicos pertenecientes a la arquitectura doméstica romana de carácter urbano en territorio valenciano, siendo objeto de estudio los núcleos urbanos de Lesera, Saguntum, Edeta, Valentia, Lucentum e Ilici. Para ello pretendemos definir el tipo de plantas y articulación espacial de las domus, estableciendo las funcionalidades de las diversas estancias (con base en la decoración, los materiales constructivos y la orientación), así como la secuencia cronológica de las mismas (fases constructivas, refacciones y abandonos), para llegar, en última instancia, a establecer patrones que nos permitan indicar rasgos de afinidad local.

Palabras clave: arquitectura doméstica romana, Lesera, Saguntum, Edeta, Valentia, Lucentum, Ilici.

\section{Current KNowledge about the URban Roman house in the area of V AlenCia}

In this article we intend to establish the state of all archaeological finds belonging to Roman domestic architecture of urban character in Valencian territory. In this paper we study the urban centers of Lesera, Saguntum, Edeta, Valentia, Lucentum and Ilici. To do this we aim to define the type of plants and spatial articulation of domus, establishing the functionalities of the various rooms (based on decoration, building materials and orientation) and the evolution of the rooms (construction phases, repairs and abandonments). Our final aim is to establish patterns that allow us to indicate features of affinity in the local constructions.

Key words: Roman domestic architecture, Lesera, Saguntum, Edeta, Valentia, Lucentum, Ilici.

En el presente artículo pretendemos trazar un panorama sobre el conjunto de evidencias arqueológicas pertenecientes a la arquitectura doméstica romana de carácter urbano en el territorio valenciano. Partimos del hecho de que hasta el presente, dicho aspecto ha sido abordado de forma muy limitada en el marco de la investigación arqueológica sobre la presencia romana en el área objeto de estudio. Los estudios precedentes resultan todavía muy escasos y, por lo general, se han dedicado a presentar casos particulares sin una perspectiva de conjunto. Esta situación deficitaria tuvimos ocasión de resaltarla en nuestro trabajo final del Máster en Arqueología por la Universitat de València, titulado Estado de la cuestión sobre la arquitectura doméstica romana urbana del área valenciana, y que ha constituido la base desde la que pretendemos desarrollar nuestro proyecto de tesis doctoral. Con esta finalidad, estamos elaborando un corpus intentando identificar y definir los distintos tipos de plantas y la articulación espacial de los elementos residenciales con base en las tipologías constructivas, materiales y cuando existan evidencias, en los programas decorativos. Resulta fundamental el estudio de las plantas para poder determinar las distintas estancias 
y espacios domésticos, tratando de distinguir entre espacios de recepción, espacios privados y de servicio. Asimismo, de cara a establecer su función, es preciso contemplar aspectos como la ubicación en el espacio, su orientación, sus dimensiones y los tipos de decoración. Igualmente, reviste importancia concretar, en la medida de lo posible, la secuencia cronológica de cada domus, indicando las distintas fases constructivas, reformas y abandono. Como ya apuntaba Balil, la excavación de una casa romana es difícil y costosa, pues es imposible predecir hasta qué punto se deberán extender los trabajos para descubrir la totalidad de la vivienda. Por tanto, se debe abogar por una excavación completa de la estructura de la domus, renunciando a los simples perfiles o secuencias estratigráficas (Balil 1972: 58).

Por otra parte, resulta interesante confrontar la entidad del registro arqueológico de cada ciudad con el fin de proponer patrones o modelos, que nos puedan indicar

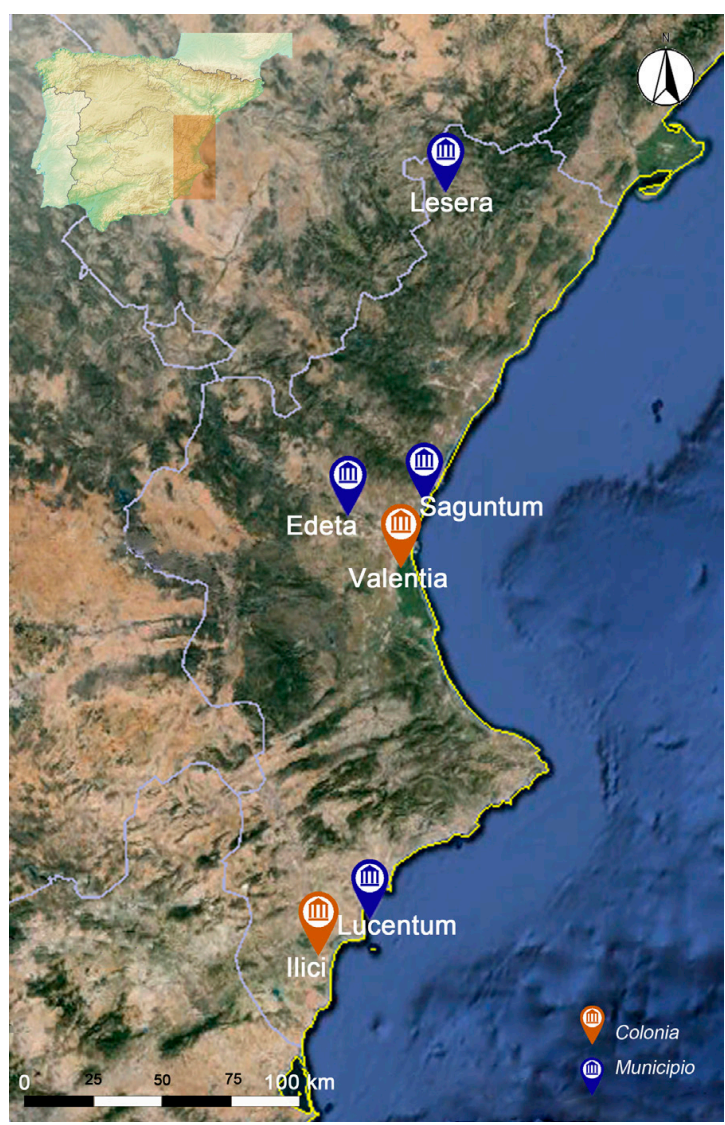

Fig. 1. Mapa del territorio valenciano con la situación de las ciudades romanas estudiadas. rasgos de afinidad a nivel local, así como con poblaciones vecinas; incluso con la península Itálica, una vez demostrada la fuerte influencia de costumbres y modas propias, aportadas por los contingentes itálicos que se desplazaron a la península Ibérica dentro del proceso de control territorial ejercido por Roma, durante los dos últimos siglos de la República.

Finalmente, se pretende superar el análisis meramente arquitectónico y descubrir la esencia de la casa, como materialización de un status social y en definitiva, como la cristalización de un microcosmos, donde confluyen circunstancias sociales, económicas, políticas, culturales y religiosas.

Tomando como referencia el Congreso celebrado en 1988, en Zaragoza, sobre La casa urbana hispanorromana, hemos podido constatar que, transcurridos veinticinco años desde entonces, el conocimiento de la vivienda romana en el área valenciana sigue siendo muy deficiente. Esta parquedad de estudios contrasta con el incremento espectacular en el número de intervenciones arqueológicas registrado en España en las últimas tres décadas, en un alto porcentaje de carácter urbano, siendo Valencia una de las ciudades más pródigas en actuaciones arqueológicas. La principal consecuencia de tan extraordinario auge ha sido la generación de un ingente volumen de datos que en una gran proporción apenas ha sido incorporado al cuerpo general del conocimiento histórico. Esta situación, que supone uno de los principales retos a los que debe hacer frente la investigación arqueológica a más corto plazo, se manifiesta de forma más acusada en el ámbito de la arquitectura doméstica romana, que siempre ha figurado en un segundo plano, eclipsada por las grandes construcciones públicas que, por lo general, han sido objeto de un mayor interés a la hora de ser estudiadas. Es por esto que es necesario plantear un estudio de conjunto de los aspectos materiales de las viviendas, insertándolas en el urbanismo de las ciudades mediante un proceso de excavación y análisis íntegro. No podemos olvidar la desigualdad de conocimiento entre nuestras domus y la necesidad de reinterpretar antiguas excavaciones. Esta es la razón de que el trabajo de Beltrán sobre los modelos de la casa hispanorromana se convierta en otro referente para nuestro estudio (Beltrán 2003: 13-63).

El territorio objeto de estudio, atravesado por la Via Augusta, cuenta con importantes ciudades, caso de Lesera (Forcall), Saguntum (Sagunt), Municipium Edetanorum (Llíria), Valentia (València), Saetabi (Xàtiva), Dianium (Dénia), Lucentum (Tossal de Manises), Alone (La Vila 
Joiosa) e Ilici (Elx), que de manera conjunta ofrecen un panorama muy interesante de la presencia romana en esta parte de la costa mediterránea peninsular (fig. 1). Un territorio que fue escenario de episodios históricos de gran repercusión, primero en el transcurso de la contienda romano-cartaginesa y seguidamente, en el largo proceso de conquista y control territorial de la península Ibérica por parte de Roma. Esta etapa que cubre los dos últimos siglos a.C., supuso la llegada de tropas y de gentes de procedencia itálica y con ellas, la introducción de todo tipo de influencias culturales que de forma lenta pero imparable, fueron calando en las comunidades ibéricas de contestanos y edetanos (Jiménez 2007: 140-142).

\section{EVIDENCIAS ARQUEOLÓGICAS DE DOMUS URBANAS EN TERRITORIO VALENCIANO}

\section{ÉPOCA REPUBLICANA}

Para la etapa cronológica que comprende los dos últimos siglos de la República, el principal problema viene representado por la tremenda escasez de evidencias materiales. Buena prueba de ello es que debamos recurrir a exponentes como el pavimento de mosaico hallado en L'Alcúdia (Elx). Esta incripción ha sido fechada por Abad en un avanzado s. II a.C. o a comienzos del s. I a.C., mientras Ramos y Uroz la datan en cierto momento del s. II a.C. y Gómez Pallarés la sitúa ya en la segunda mitad del s. I a.C. A pesar de las diversas lecturas, todos los investigadores parecen aceptar que el texto contiene cuatro o cinco nombres ibéricos escritos en alfabeto latino, lo que nos permite intuir los primeros rasgos de romanización (fig. 2). La hipótesis de Gómez Pallarés relaciona la decoración no figurada con la posible financiación y utilización del mismo (Abad 1989: 159-167; Corell 1999: 78-79; Fernández 2004: 167-174; Gómez Pallarés 1997 : 38-39; Sarabia y Cañavate 2009: 89-110).

En el caso de Valentia, las manifestaciones de esta etapa se reducen a los restos de viviendas hallados en el Palau de Benicarló, actual sede de Les Corts Valencianes (fig. 3) (Marín y Matamoros 1994: 39-178). Hemos de decir que los restos aparecieron bastante deteriorados debido a la acción constructiva de una casa imperial que se hallaba encima, así como por una gran fosa de expolio de época tardorromana que arrasó la parte central de la zona excavada hasta el nivel estéril. Se excavó en extensión abarcando 339 m² por $5 \mathrm{~m}$ de profundidad (Marín et al. 1991: 61-63).

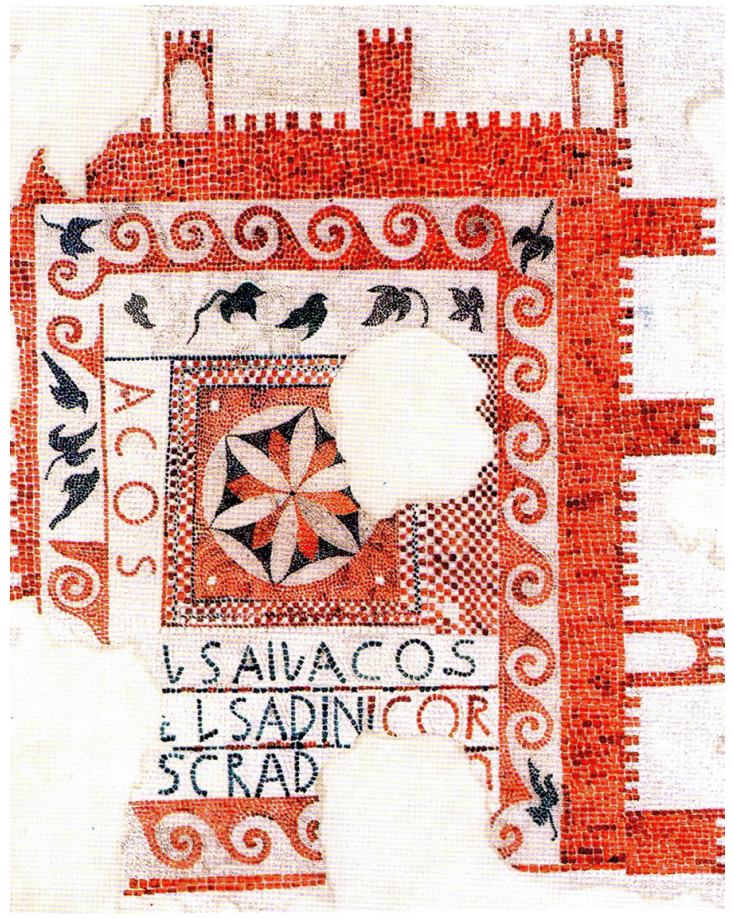

Fig. 2. Calco del mosaico de tipo helenístico. L'Alcúdia, Elche (Fernández 2004).

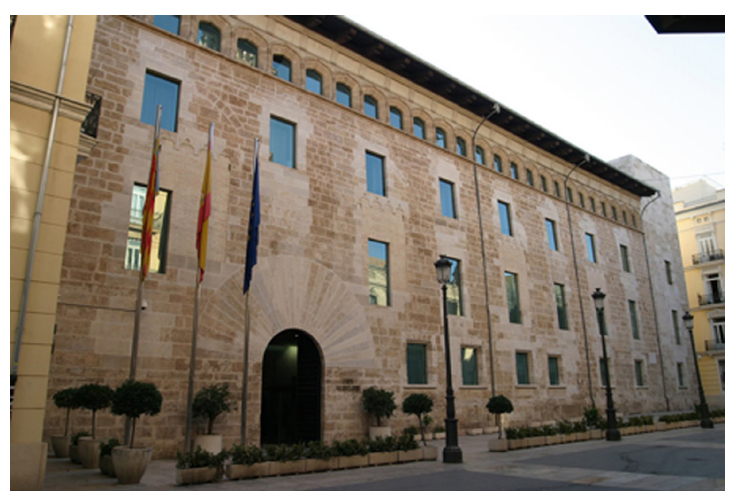

Fig. 3. Palau de Benicarló, sede de Les Corts Valencianes, València.

Desde el punto de vista estratigráfico podemos distinguir tres momentos dentro de la etapa republicana. La primera fase constructiva se caracteriza por su localización al O de la excavación, con grandes espacios abiertos, sin muros medianeros, pavimentos de cal sobre una capa de grava aislante y muros de mampuesto. En el sector E se encontró un área con pavimentos en contacto con el estrato fundacional. 


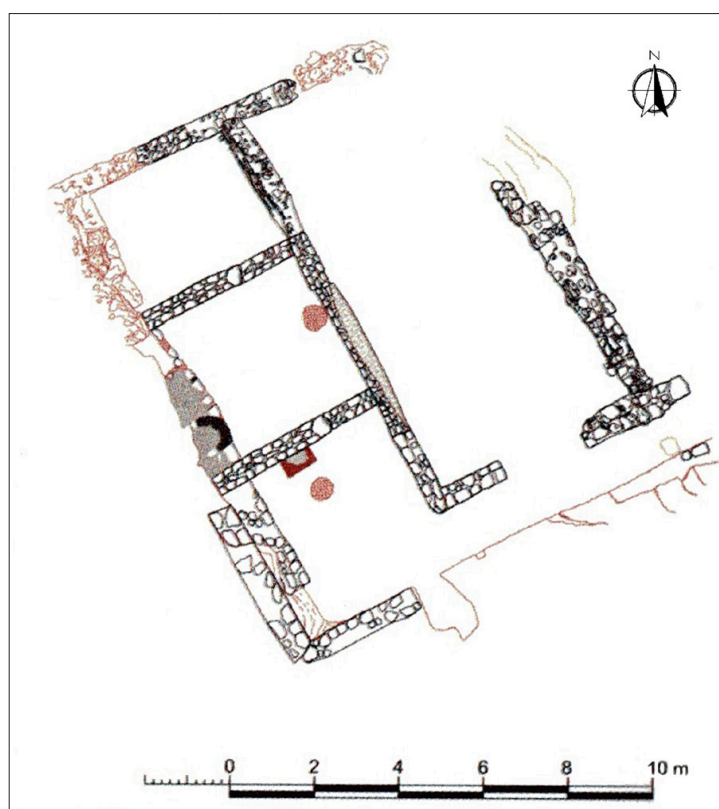

Fig. 4. Planta de la tercera fase. Lesera (Forcall) (Arasa 2009).

No se registraron indicios de esta fase en el área central, que podría funcionar como zona de esparcimiento común (Marín y Matamoros 1994: 48-50).

En la segunda fase constructiva, se eliminaron los muros longitudinales, para dar paso a una nueva planta en la que las dimensiones se reducen, articulando pequeños departamentos como prueba de una mayor planificación y compartimentación del hábitat. Esta división aparece en toda la superficie excavada, aunque la gran fosa tardorromana ha alterado las estructuras haciendo imposible su puesta en relación (Marín et al. 1991: 63-64).

En un primer momento se propuso una tercera fase constructiva, aunque actualmente se plantea como una remodelación arquitectónica, donde los departamentos sufren refacciones, con nuevas pavimentaciones y mejoras técnicas en los muros de nueva factura, realizados con mampostería más regular (Marín et al. 1991: 64).

El momento final viene marcado por un nivel de incendio, en el que se destruyeron todas las estructuras, documentado por una potencia estratigráfica de $50 \mathrm{~cm}$ compuesta por adobes quemados, tegulae, dolia y abundante material cerámico. Su abandono giraría en torno a la primera mitad del s. I a.C. (Marín et al. 1991: 65). Este episodio afecta directamente a las pavimentaciones y, sobre todo, al sector $\mathrm{O}$, estando los pavimentos y sus preparaciones totalmente calcinados. No se puede dar una interpretación

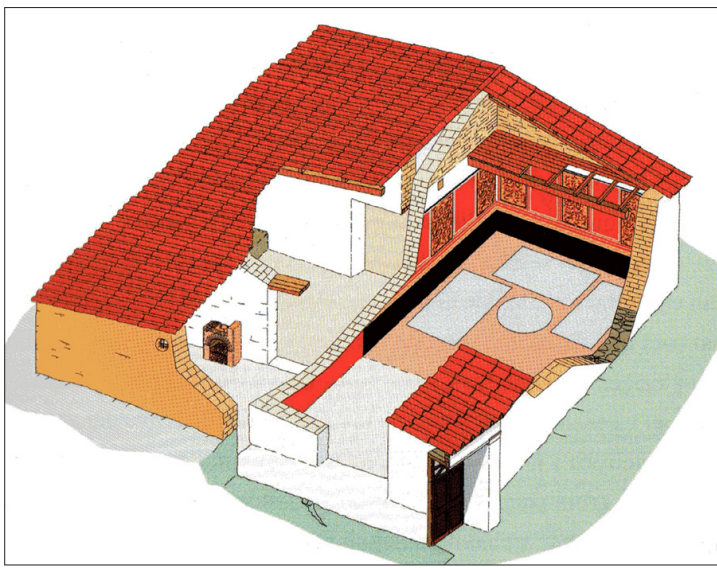

Fig. 5. Dibujo con la reconstrucción de la domus en la tercera fase. Lesera (Forcall) (Arasa 2009).

concreta del plano general de este asentamiento, ya que el estudio posicional de los restos cerámicos no arroja luz en este aspecto. Sin embargo, este episodio está reflejado en otros puntos de Valentia como la Almoina, donde se recuperaron, además, cuerpos mutilados con abundantes armas, indicando un episodio bélico que podría constatar el traumático impacto que causó en Valentia la guerra civil entre Sila y sus enemigos en Hispania, representados por Sertorio (Marín y Matamoros 1994: 53-54).

Pese a su escasa entidad, por el momento, se trata de la única muestra de arquitectura doméstica de la Valentia republicana, que revela un tipo de edificación modesta con paredes de tapial levantadas sobre zócalos de mampostería regular, cubiertas con tegulae e imbrices, con suelos de tierra apisonada o lechada de cal sobre preparación de grava.

\section{ÉPOCA IMPERIAL}

El Principado del emperador Octavio Augusto, una vez concluido el proceso de conquista de la península Ibérica, marcó el inicio de un periodo de estabilidad que propició un cambio radical en la imagen de las ciudades, tanto en las viejas y leales durante la conquista, como en las colonias de nueva creación. Como no podía ser de otra forma, las ciudades romanas del actual territorio valenciano fueron partícipes de esta etapa de prosperidad reflejada en sus volúmenes arquitectónicos de gran aparatosidad, como los teatros (Saguntum) y circos (Saguntum y Valentia), o los foros, grandes espacios que albergaban las principales funciones urbanas (gobierno municipal, edificios religiosos, administrativos y judiciales). En la 
misma medida, la arquitectura doméstica experimentó grandes cambios traducidos en una mayor diversidad de modelos y en la introducción de nuevos programas decorativos.

La intensa actividad arqueológica desarrollada en el territorio en cuestión en los últimos años está proporcionando ejemplos interesantes de residencias urbanas, aunque se dan fuertes desigualdades de conocimiento entre unas ciudades y otras.

\section{LESERA}

En las primeras campañas de excavación realizadas entre los años 2001 y 2004 se descubrieron los restos de una modesta residencia de época imperial, con tres fases constructivas que abarcan más de 150 años. La domus se encontraría adosada a otras casas, siendo la que presentaba un mejor estado de conservación (Arasa 2009: 62-73).

La primera fase se corresponde con las últimas décadas del s. I a.C., realizada con materiales pobres, con paredes de piedras trabadas con barro y pavimentos de tierra batida. La planta estaría dividida en dos partes desiguales, separadas por un muro con función estructural sobre el que descansaría un techado a dos aguas. Cada una de las partes se dividía en tres estancias, la puerta de entrada ( $2,40 \mathrm{~m})$ daría a la habitación central donde se ha hallado un hogar. En el exterior, bajo un porche y en el lado $\mathrm{S}$ de la fachada, se han encontrado dos muros perpendiculares que daban soporte a un pequeño horno doméstico. $\mathrm{Al}$ menos dos muros de esta casa han conservado restos pertenecientes a piezas de madera, lo que podría formar parte de un entramado, representando una estructura mixta. Esta fase aparece arrasada por un nivel de incendio (Arasa 2009: 62-66).

La segunda fase es la peor conocida, en la que se reorganiza la planta construyendo un pasillo que conectaba la calle con las distintas estancias, la fachada avanza y se establecen nuevas habitaciones. Fue destruida pocas décadas después de su construcción y parece que su ocupación se corresponde con el s. I d. C.

La tercera fase es la mejor preservada y su planta rectangular conserva la división en dos partes siguiendo el eje paralelo de la fachada y un pasillo distribuidor (fig. 4). La cubierta es de tejas y los pavimentos de tierra batida. Presenta una gran sala rectangular identificada como triclinium, ya que sus dimensiones destacan sobre las demás estancias. Además, se han encontrado paralelismos con otras domus como la Casa de Hércules y la Casa de los Delfines (en Victrix Iulia Celsa), cuyos comedores presentan la misma planta rectangular. Las otras estancias son de carácter doméstico (una cocina y un área de artesanía textil). La casa fue abandonada a mediados del s. II d.C., y sus ocupantes se llevaron consigo los objetos de valor, por lo que apenas se han recuperado restos.

El triclinium se encuentra decorado con pinturas murales y molduras de yeso. La decoración tendría dos fases, el esquema compositivo presenta un zócalo con imitación de mármol, una zona intermedia con paneles rojos e interpaneles negros y una zona superior con una cornisa. Como hemos podido comprobar en otras domus del territorio valenciano la imitación del mármol brocatel es frecuente en estancias principales (fig. 5).

En esta domus se aprecia la progresión del proceso de romanización en las distintas fases, desde una primera fase cuyos rasgos confirman la tradición arquitectónica ibérica hasta una tercera fase con rasgos inequívocamente romanos (Arasa 2009: 66-73).

\section{SAGUNTUM}

De la antigua Saguntum destacan los restos de la domus documentada en 2002 bajo el solar que ocupaba el antiguo cine Marvi, y que ha sido objeto de una reciente

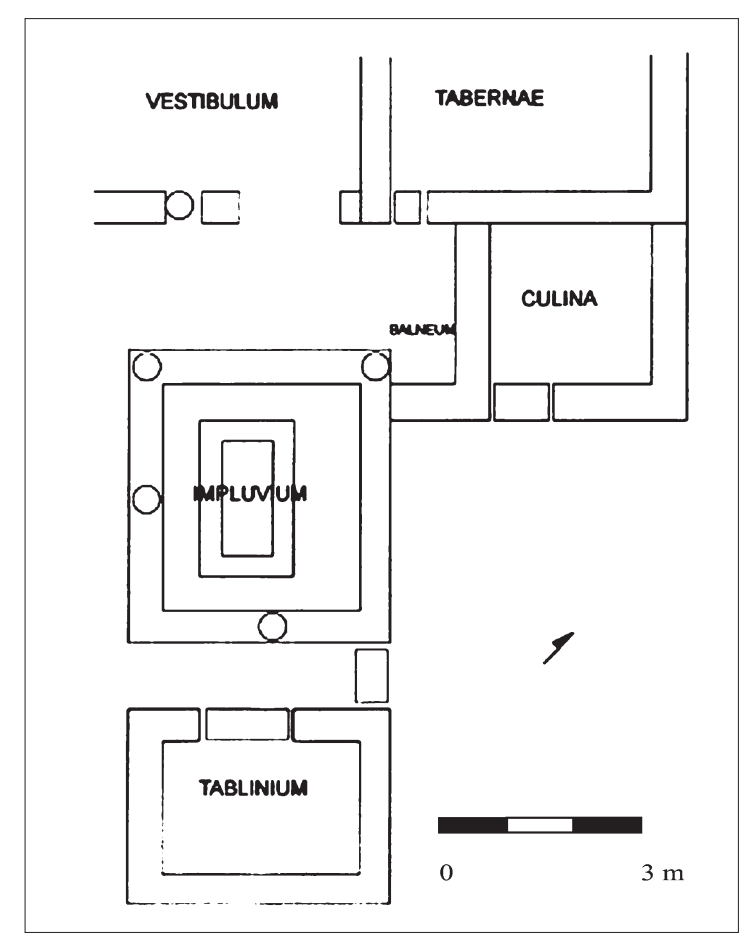

Fig. 6. Plano de la Domus dels Peixos. Sagunt (Antoni et al. 2006). 


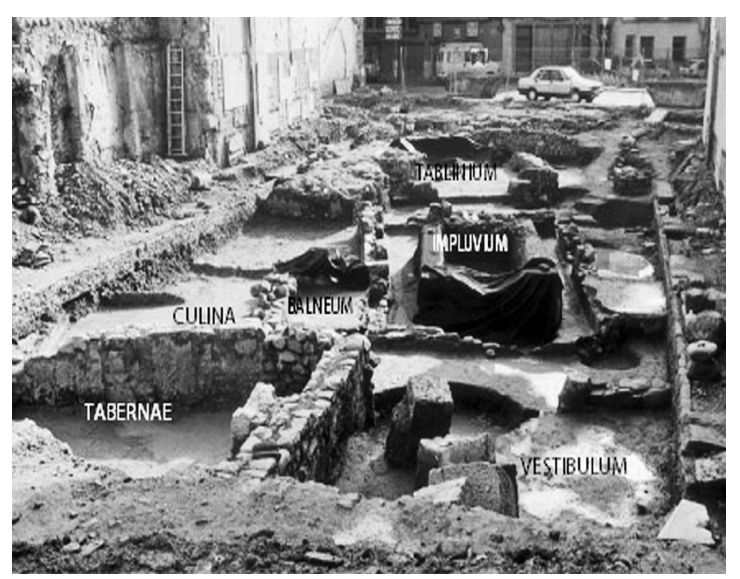

Fig. 7. Domus dels Peixos. Vista general de la domus y sus distintas estancias. Sagunt (Antoni et al. 2006).

puesta en valor bajo la denominación de Domus dels Peixos. Se trata de un ambiente doméstico datado en el s. II d.C. con una remodelación en el s. III d.C. y un abandono en el s. IV d.C., que ofrece un magnifico estado de conservación, con ricas ornamentaciones, buen reflejo del nivel económico y gustos decorativos de sus propietarios.
El inmueble sigue un eje axial que ordena los espacios en torno al atrio o patio porticado. Gracias a los materiales y a las estructuras ha podido determinarse la función de cada una de las estancias. La domus constaba de una taberna, de la que se recuperó una importante cantidad de cerámica y recipientes de almacenaje, señal de que en este espacio se desarrollarían actividades económicas. Inicialmente, estaría comunicada con la domus a través de un vano que se cerró posteriormente, lo que permite deducir que la taberna pasó a manos de un propietario externo a la familia (fig. 6).

Esta domus poseía un atrio o patio corintio, con su correspondiente impluvium, del que se han podido identificar cinco elementos arquitectónicos verticales, con fustes de $30 \mathrm{~cm}$, de los cuales uno conserva restos de pintura en azul y rojo. Por su parte, el impluvium presenta el revestimiento hidráulico característico y, además, una decoración pictórica en el lecho interior con composiciones de peces y elementos marinos como elemento suntuario, costumbre equiparable a la constatada en viviendas africanas como la Casa de Baco (Cuicul) y la Casa de Sertius (Timgad), donde se presentaban peces vivos.

Se pensó que la estancia donde culmina el diseño axial con el pavimento sobreelevado respecto al atrio, estaba destinada a la recepción de la clientela por parte del

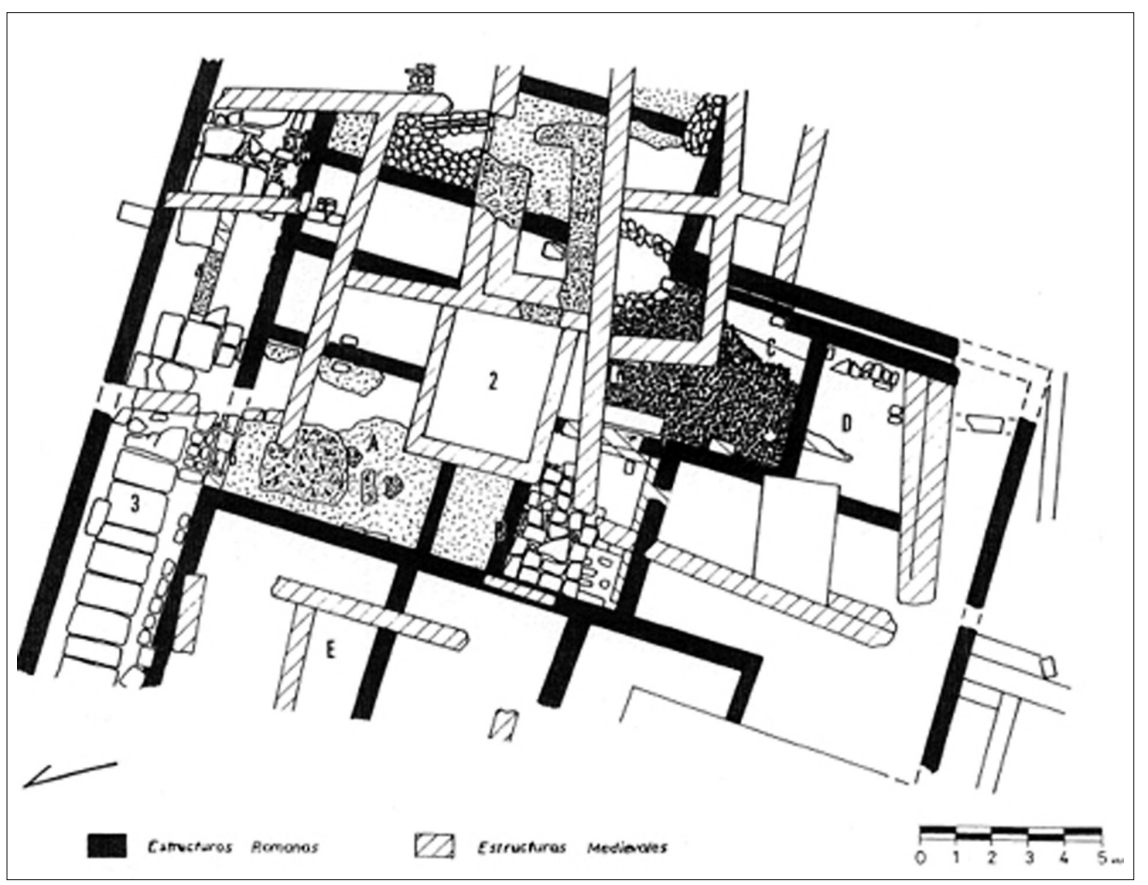

Fig. 8. Planta general de una de las domus del solar de la Morería Vella, Sagunt (Chiner y López 1994). 
patronus, razón por la que los investigadores la interpretaron como tablinum. Sin embargo, su morfología nos hace cuestionarnos esta interpretación inicial, ya que podría tratarse de una habitación central abierta a un patio porticado. Parte de la decoración pictórica se ha conservado in situ, concretamente, un zócalo de mármol en la parte inferior, y una zona central que combina los paneles anchos con interpaneles estrechos (fig. 7).

Pasando a la zona de servicio, de la culina no hay indicios estructurales de hogares u hornos, que se situarían en el patio. Los materiales aparecidos se corresponden con el tipo de cocina, almacenaje y numerosos fragmentos de dolia. Junto a la culina se encontraba una estancia, con un pavimento de mortero hidráulico, interpretada por los descubridores como un baño privado añadido al plano en una segunda fase constructiva. Su situación junto a la culina demostraría la típica asociación de baño/cocina para aprovechar el agua caliente. Además, se encuentra orientado hacia el O para captar el calor y la luz de la tarde (Antoni et al. 2006: 99-114). Sin embargo, su reducido tamaño y la ausencia de hypocaustum nos permiten cuestionarnos esta interpretación.

En la excavación del solar de la Morería Vella, que afectó a más de $1700 \mathrm{~m}^{2}$, salió a la luz un barrio doméstico con indicios de planificación urbana, localizándose una serie de estancias de carácter doméstico cuya funcionalidad aparece definida por las estructuras y los materiales encontrados en ellas. En este espacio, presumiblemente doméstico, se encontró un patio con salida directa a la calle, alrededor del cual se organizan el resto de estancias: un almacén, posible granero, que presenta una zona pavimentada con losas de rodeno sobreelevadas; un patio pavimentado con cantos rodados y cobertizo, con abundantes fragmentos de dolia; una estancia enlosada con un horno en el que se recuperaron restos de vajilla de mesa y cocina y una dependencia que no parece tener relación espacial con el resto de estancias, donde se hallaron objetos de adorno personal y un lote monetario. Esta domus se abandonaría en torno al s. IV d.C. (fig. 8) (Melchor y Benedito 2005: 12-25).

\section{EDETA}

Edeta ha deparado dos hallazgos destacados, uno antiguo, la Casa del Mosaico de Hércules, denominación que se debe al pavimento en opus tessellatum que representa las doce tareas del héroe en perfecto estado de conservación, y otro más reciente, la Casa del Tesoro (Calle Duc, $\mathrm{n}^{\circ}$ 50-52, Llíria), donde se documentó un depósito monetario formado por 5990 denarios de plata, escondido en una modesta estancia. A tenor de la fecha proporcionada por las monedas, la ocultación debió producirse a principios del s. III d.C. (Escrivà et al. 2001: 66-74; Delegido 2011: 679).

En 1917 apareció el conocido mosaico de los doce trabajos de Hércules a $2 \mathrm{~m}$ de profundidad, en Ca Porcar (Arasa 2000: 146). La domus fue excavada por su propietario, Francisco Porcar, que en diversas ocasiones había colaborado con el SIP de la Diputación de Valencia. Se conservan fotografías del archivo de la Diputación de diversos objetos de época romana dispersos por el patio de la casa. Resulta problemático determinar si todos ellos procedían de la casa, porque Porcar fue, además, coleccionista de piezas arqueológicas (Escrivà et al. 2001: 70; Balil 1978: 265-275).

En su lado N, se encontraron las huellas de una puerta, que podría dar paso a otras habitaciones interiores y, por otra parte, en el lado E, una puerta mayor queda marcada por las señales de quicios laterales. Asimismo, se encontró una estancia pavimentada provista de un hypocaustum, identificada por los investigadores como el hogar de un horno cerámico, asociación que se pudo realizar por su función calefactora (Escrivà et al. 2001: 70). Entre los hallazgos destaca un oscillum de mármol blanco (Arasa 2000: 145-146). El mosaico de 5,40 x 4,60 m, está ocupado por doce recuadros con representaciones de los athloi o fatigas de Hércules, que giran en torno al tema central donde aparece representada a la reina de Lidia

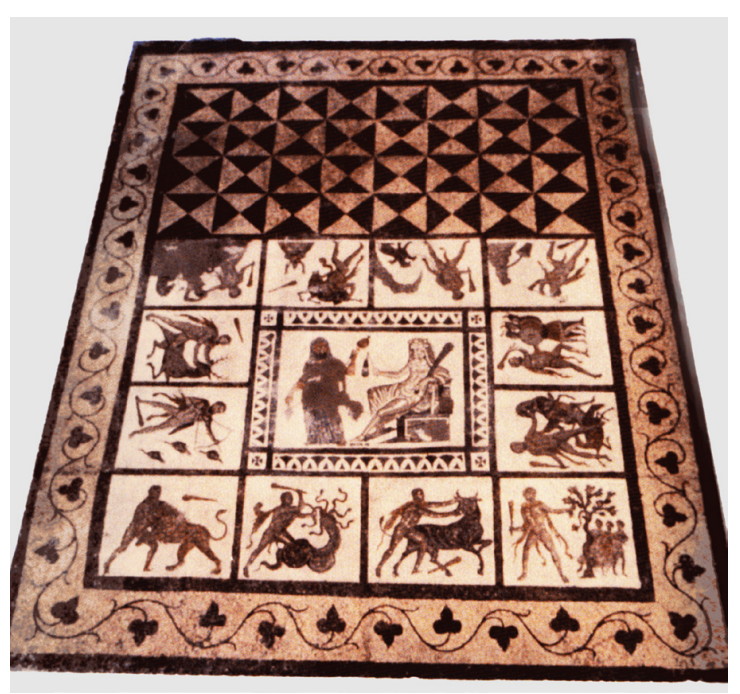

Fig. 9. Mosaico de los Trabajos de Hércules, MAN. Llíria (Montesinos y Buchón 2011). 
cubierta con la piel del león de Hércules, mientras éste hila lino a sus pies. Llama poderosamente la atención la elección de este tema como emblema central del mosaico (Escrivà et al. 2001: 70- 73), en el que aparece Hércules como esclavo y además, con una vestimenta femenina (fig. 9). En Hispania encontramos paralelos temáticos en las pinturas aparecidas en la Casa de Hércules, en la colonia Lepida-Celsa, situadas en las paredes de un oecus triclinar que se corresponden con los motivos de Hércules y el jabalí de Erimanto, Hércules y la cierva Cerinia, la escena de las aves del Lago Estínfalo y una última escena interpretada como Hércules niño (Mostalac y Beltrán 1996: 239-259). De igual modo, se representan los athloi en el mosaico hallado en Cártama a finales del s. XIX, aunque sin reproducir el mismo modelo, pues en este caso en ninguna de las fatigas aparece Hércules, sino sus enemigos vencidos (Balil 1977: 371-379). Dados sus paralelos y la excepcionalidad del mosaico consideramos que estaría situado en una estancia relevante de la vivienda, posiblemente con funciones de tablinum o de triclinium, ya que la disposición de los lechos permitiría disfrutar del motivo central del pavimento.

Cerca de la ubicación de esta domus, en la avenida del Pla de 1'Arc, se registró un espacio rectangular limitado por unos muros de argamasa, que presentaba una moldura de media caña rellenada con tegulae, con una fecha en torno al s. II d.C., se ha barajado la posibilidad de que pudiera estar conectado con la casa del mosaico, sin que haya sido posible establecer el grado de relación (Escrivà et al. 2001: 73-74).

La Casa del Tesoro presenta el inicio de su construcción en torno a la segunda mitad del s. I d.C., aunque no resulta posible precisar sus límites, ya que se hallan bajo las casas colindantes. A juzgar por los restos documentados, se trata de una casa con atrio o patio central descubierto, que consta de un impluvium excelentemente conservado con recubrimiento hidráulico, moldura de media caña y un sumidero, rodeado por un pórtico cuyas columnas han dejado huella en el pavimento. Es posible que la domus presentara más de una planta. En cuanto a técnicas constructivas, la fachada trasera se realizó en opus quadratum, empleando grandes sillares de piedra, mientras que en la parte interior se empleó, además del opus quadratum, el opus vitattum y opus africanum. Por lo que se refiere a los pavimentos, los hay de opus signinum y otros de ladrillo, sencillez que contrasta con la decoración pictórica de las paredes. La habitación en la que apareció el tesoro, situada en la parte $\mathrm{S}$ del ala $\mathrm{E}$, con acceso desde el atrium es de las más sencillas, la única cuyos muros interiores se conforman por grandes sillares (fig. 10).

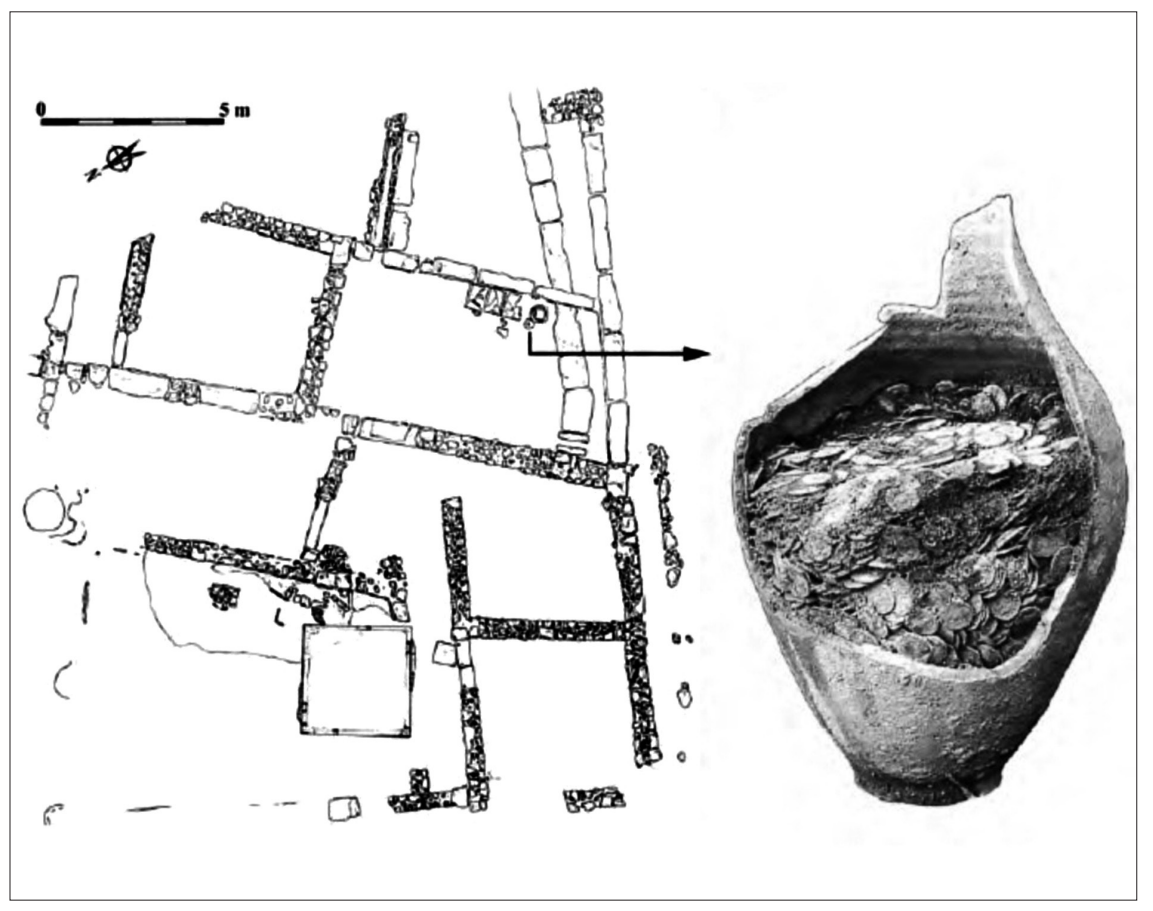

Fig. 10. Planta de la Casa del tesoro y fotografía de la jarra con las monedas. Llíria (Gozalbes et al. 2005). 
La casa fue abandonada en torno al 260-270 d.C., utilizándose posteriormente para rituales votivos. Esta domus podría guardar relación con una excavación, en la calle Sant Miquel ${ }^{\circ} 8$, donde aparecieron restos constructivos romanos (Escrivà et al. 2001: 67-70).

\section{VALENTIA}

\section{La denominada Domus de Terpsícore}

Ya se ha hecho referencia a los restos de construcciones domésticas de época republicana que se documentaron en las excavaciones realizadas en el Palau de Benicarló, sede de Les Corts Valencianes y que debieron quedar destruidas en el transcurso de las guerras sertorianas. La investigación arqueológica ha constatado que solo a partir de la época Flavia se materializó una nueva fase constructiva no reutilizándose estructuras precedentes. En la publicación de los resultados de esta intervención se propuso la construcción de una domus en época Flavia cuya distribución espacial no llegó a definirse, a excepción del impluvium del atrio, debido a que fue objeto de una profunda reforma en la segunda mitad del s. II d.C., aunque se mantuvo la planta primitiva (Marín y Matamoros 1994: 123). Este inmueble debía compartir la misma insula con otro situado al $\mathrm{O}$, de acuerdo con la interpretación de un muro como medianero entre ambas viviendas. Este detalle es relevante porque permite deducir los límites de la insula, al O por un cardo, la actual calle Navellos y al E, por el cardo maximus, actual calle Salvador.

A juicio de los responsables de la intervención, la domus de época antonina se adaptaba al modelo de planta itálica, acogiendo ciertos valores provinciales (Marín y Matamoros 1994: 126). Sin embargo, en la interpretación que se hace de la planta, hay diversos aspectos que plantean dudas. Así, en el caso del atrio, resulta extraño que el impluvium de la fase antonina, construido sobre el emplazamiento del precedente de época Flavia, quede desplazado respecto del centro del atrio y que esta operación acarrease el desplazamiento de una de las vigas de la cubierta (Marín y Matamoros 1994: 128-129). Igualmente, no se arguye de manera suficiente la identificación del tablinum, situado al O del atrio, que quedaba enfrentado a otra estancia a la que se accedía desde el lado E del mismo, interpretada como triclinium sin argumentos de peso (Marín y Matamoros 1994: 130-131). La zona que queda al S del atrio es la que se vio más afectada por la gran fosa de época tardorromana. Aun así, se identificó un posible pasillo que daba acceso a tres habitaciones en muy mal estado de conservación, aunque por sus dimensiones, dos de ellas pudieron actuar como cubicula (fig. 11).

Fig. 11. Reconstrucción hipotética de la domus en la fase Antonina. València (López et al. 1994).

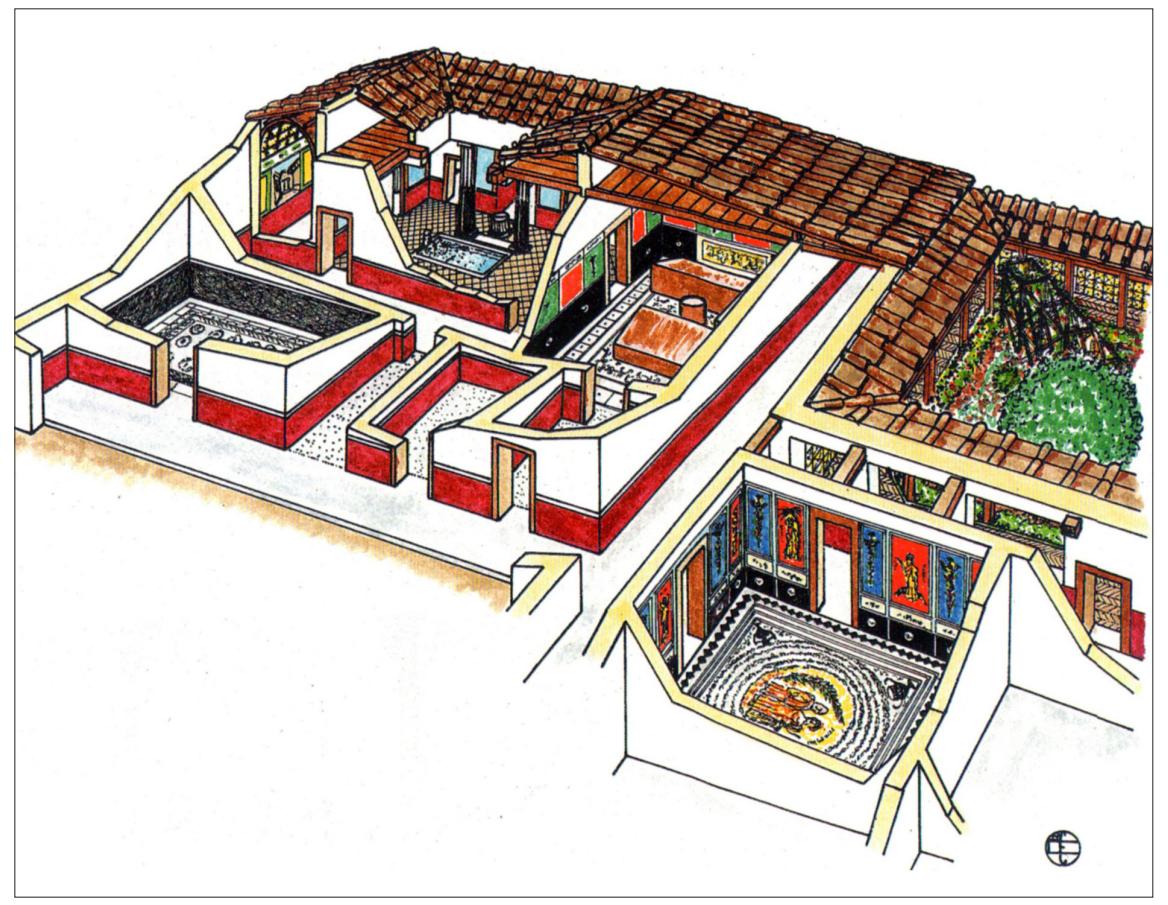


Un mejor estado ofrecía la zona situada al E del atrio, articulada en torno a lo que pudo ser un hortus, pavimentado en opus spicatum. A través del lado S del corredor que circundaba este jardín, se accedía a la estancia que ha deparado los restos de decoración más lujosa, como su pavimento de mosaico de opus tessellatum, donde la presencia de la musa Terpsícore ha servido para denominar

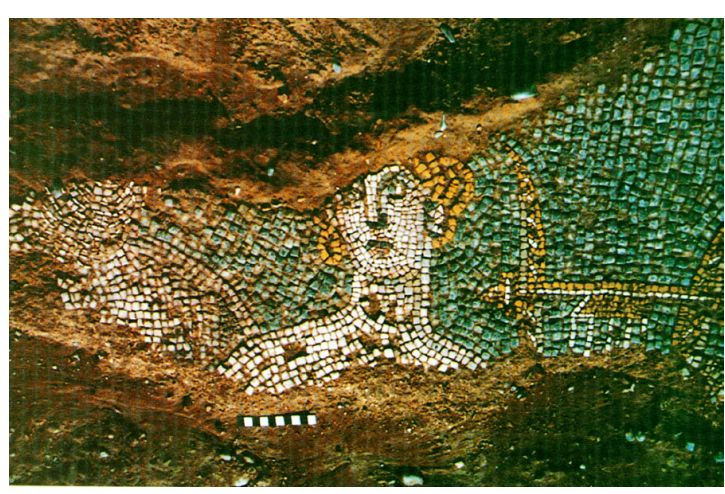

Fig. 12. Mosaico con representación de figura femenina, a su lado restos de una figura de rasgos masculinos. València (López et al. 1994).

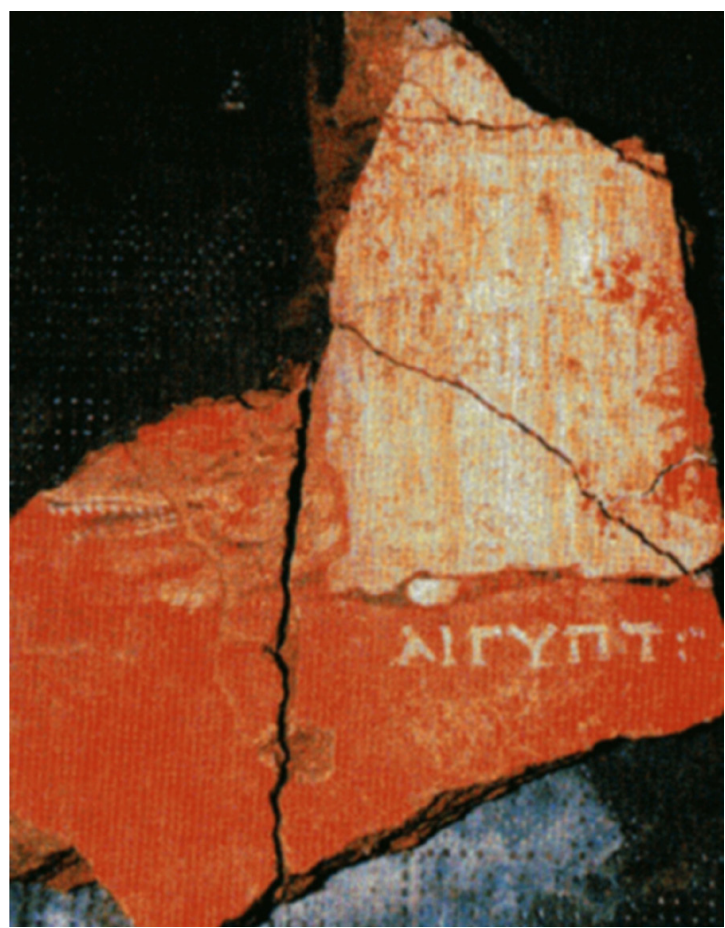

Fig. 13. Pintura mural con representación de la provincia de Egipto. València (López et al. 1994). este inmueble con el nombre de la Musa de la danza, Domus de Terpsícore (Calvo et al. 1998: 24); si bien, una figura masculina que acompaña a la Musa y una palabra en grafía latina conservada en parte, han dado pie a otras interpretaciones (fig. 12) (Corell 2009: 217). Esta estancia ha proporcionado un ejemplo excepcional de decoración pictórica, estilísticamente alineada en la corriente clasicista de la mitad del s. II d.C. (Fernández 2007: 146). Esta sala estaba decorada con representaciones alegóricas de diversas provincias romanas y naciones fronterizas del Imperio, habiéndose recuperado cuatro, de las que tres conservan el nombre escrito en carácteres griegos (fig. 13) (Krougly et al. 1997: 225-228; Guiral 2000: 21-35; Fernández 2004: 526). Dado el carácter excepcional de estas decoraciones, un estudio reciente (de Hoz 2007: 131-146), ha aportado interesantes argumentos a favor de conceder un carácter público a este inmueble, habida cuenta de que la práctica totalidad de ejemplos con representaciones de provincias del Imperio, remite a edificios públicos. En la misma línea, se ha orientado otro trabajo reciente (Escrivà et al. e.p.), donde se concluye que el edificio que albergó estas pinturas debió ser uno de los más relevantes de Valentia en el s. II d.C.

\section{Otros exponentes de arquitectura doméstica en Valentia}

En los núms. 3 y 5 de la plaza de la Almoina se realizó en 1989 una intervención arqueológica que dio como resultado la recuperación de una capilla cruciforme de época visigoda edificada sobre los restos de una domus romana (Rosselló y Soriano 1998: 40). De este inmueble se identificó su entrada que conectaba con el cardo maximus con dos muros paralelos que se corresponderían con las fauces. Al S de éstas se documentó una estancia con una superficie máxima conservada de $15,81 \mathrm{~m}^{2}$, pavimentada con opus signinum con un motivo decorativo en el centro a modo de emblema enmarcado por scutula y en el lado E, una inscripción ejecutada de manera muy tosca, que apareció incompleta. Teniendo en cuenta la superficie conservada de la estancia y su decoración pavimental, se trataría de una zona de representación y, puesto que por su posición respecto a las fauces no se trataría de un atrium, podría identificarse como un triclinium usado como comedor o como una sala de recepción (fig. 14) (Jiménez 1999: 202-205).

Al S de esta habitación, se recuperó parte de un muro correspondiente a otra estancia, quedando únicamente el zócalo cuya decoración pictórica incluía paneles anchos con imitación de mármol cipollino, alternando con paneles 
Fig. 14. Plano de la excavación de los restos romano imperiales (Jiménez 1999).

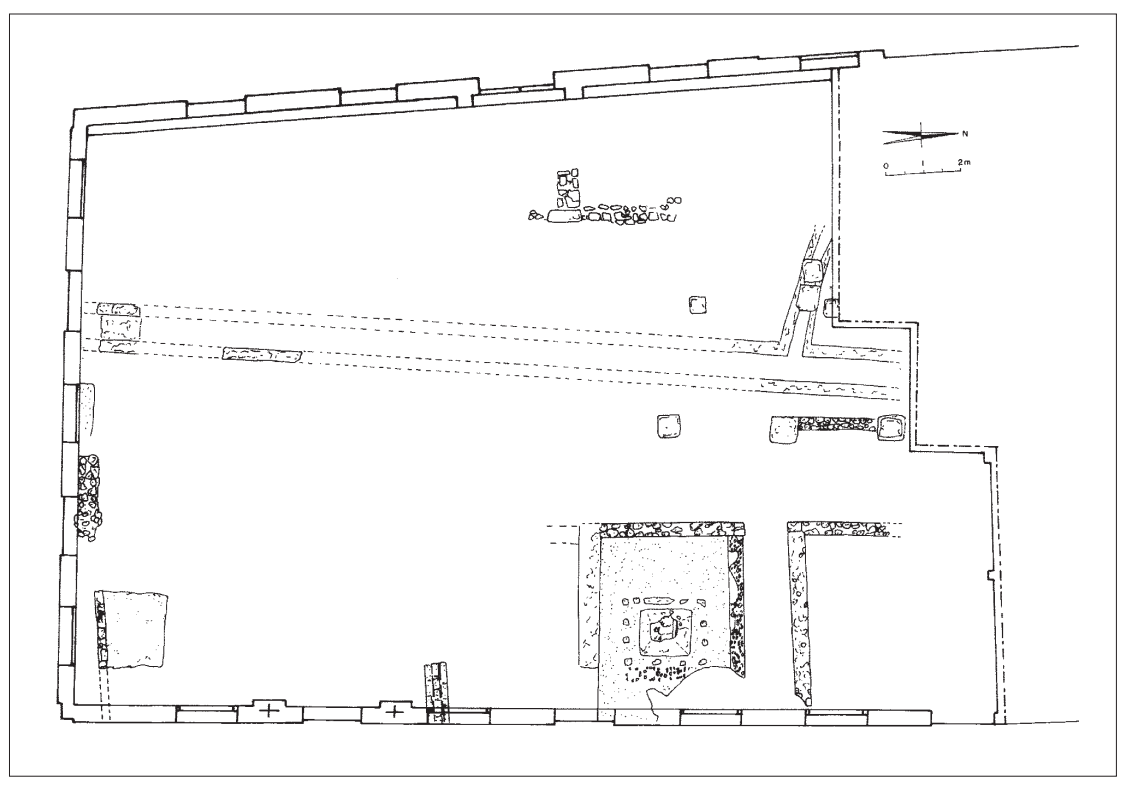

más estrechos, de los que permanecían dos, decorados con una cabeza de Mercurio y un bucráneo respectivamente. La escasa calidad técnica de estas pinturas ha llevado a plantear la duda de si la cabeza masculina corresponde a Mercurio o Hypnos (fig. 15) (Jiménez 1999: 210-212). De acuerdo con los datos de la intervención, la domus quedó amortizada a finales del s. II d.C. o inicios del s. III d.C. Sobre el nivel de amortización se documentó un habitáculo con muros en opus africanum, fechado en época bajoimperial (Rosselló y Soriano 1998: 43).

En esta revisión de otros exponentes de estructuras domésticas en Valentia, hay que excluir la supuesta domus que fue descubierta en una intervención arqueológica realizada en 1986 en el solar que ocupa el n ${ }^{\circ} 9$ de la calle Sabaters y el $n^{\circ} 6$ de la plaza de Cisneros (Albiach y Soriano 1991: 57-60). En ella se documentó un nivel de derrumbe de diversas estructuras articuladas en torno a un pasillo pavimentado en opus signinum y directamente relacionadas con la elaboración de vidrio, un tipo de actividad insalubre y, por tanto, incompatible con una función residencial. Además, las investigaciones desarrolladas con posterioridad a la intervención de 1986, apuntan a que en época altoimperial esta zona estaba ocupada por edificios dedicados a actividades comerciales y de almacenamiento de mercancías, que encajan con las características de un gran horreum (Jiménez et al. 2007: 35-43) todo ello relacionado con el puerto fluvial ubicado en sus inmediaciones (Burriel et al. 2004: 127-141).

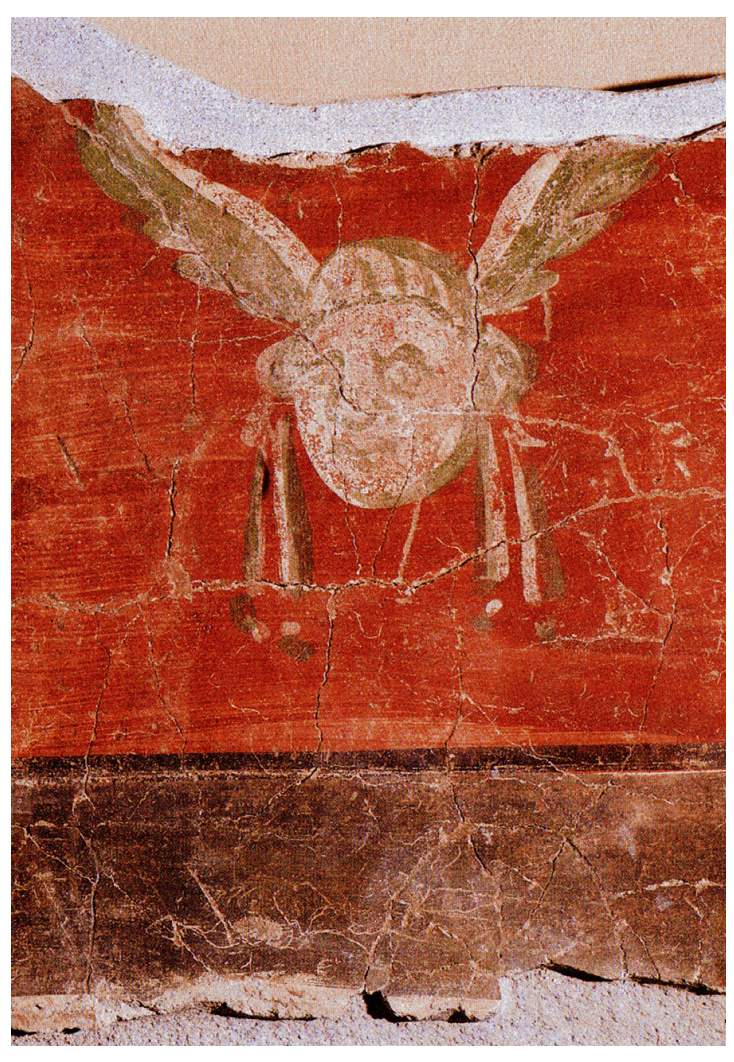

Fig. 15. Domus excavada en los núms. 3 y 5 de la plaza de l'Almoina. Pintura mural con representación de Mercurio o Hypnos. València (Rosselló y Soriano 1998). 


\section{LUCENTUM}

Lucentum representa uno de los núcleos urbanos en los que se ha registrado un mayor avance en cuanto a resultados proporcionados por la investigación arqueológica reciente (Olcina 2009: 104-114). Así, se han excavado varios inmuebles destacando las denominadas Domus del Peristilo y la Domus de la Puerta Oriental. La primera corresponde a una casa de $400 \mathrm{~m}^{2}$ perteneciente a un miembro de la élite local, cuya planta adopta forma de U con un espacio abierto dotado de una cisterna para captar el agua de lluvia, rodeada por seis pilares rectangulares. Al NO se disponían tres cubicula, y frente a éstos se abrían otras estancias que no se conservan actualmente, pues en la rehabilitación de la zona se priorizó la estructura defensiva, pero podrían, por sus dimensiones, corresponderse con el triclinium, el oecus y el tablinum. La entrada a la domus se encontraba en el extremo occidental del pórtico y se accedía mediante tres peldaños, posiblemente por la construcción de una alcantarilla que elevaría el suelo. En este caso, la domus no se adapta al modelo que ubica al atrio como eje nuclear de la casa (Beltrán 2003), ya que éste no ocupa el lugar central de la vivienda, como

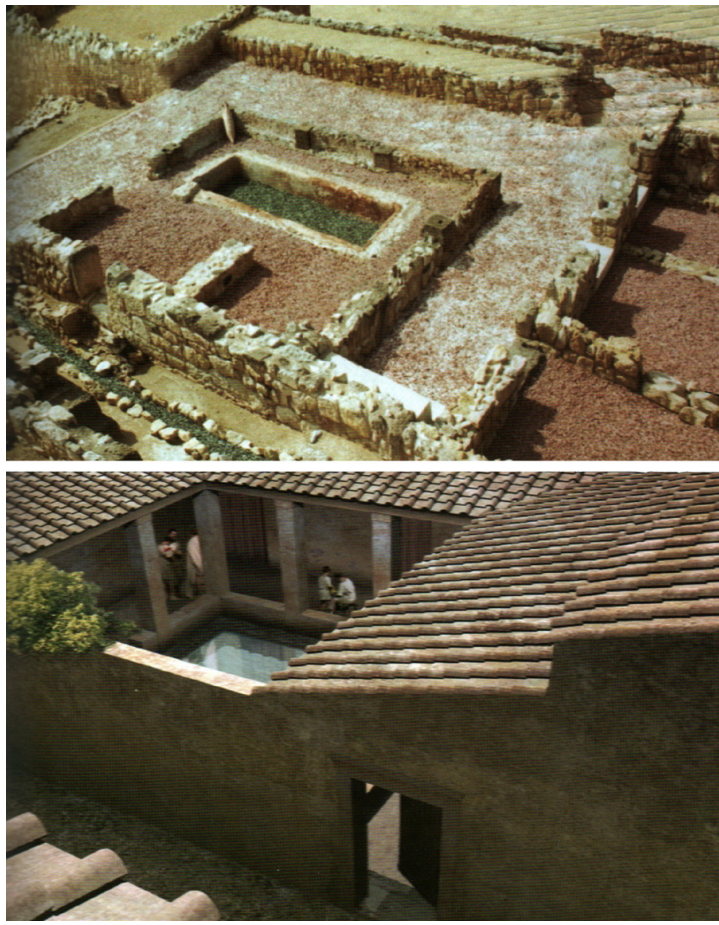

Fig. 16. Restos actuales y reconstrucción hipotética de la Domus del Peristilo. Lucentum (Tossal de Manises, Alacant) (Olcina 2009). espacio redistribuidor de estancias y, en su lugar, este papel lo desarrolla el peristilo (fig. 16) (Olcina 2009: 106-108). Sin embargo, recientes análisis de visibilidad demuestran que ha sido concebida en base a una planificación axial, en la que se busca una perspectiva óptica que permita ver desde la entrada la sucesión de estancias de carácter público, lo que se relaciona con la salutatio, saludo matutino de las clientelas al dominus (Sarabia 2013:181)

La Domus de la Puerta Oriental, que destaca por la extraordinaria conservación de sus pinturas murales, presentaba cinco estancias y un espacio aterrazado que podría constituir un jardín (viridarium) con una cisterna a uno de sus lados que se abandonó a finales del s. II d.C. En la habitación $\mathrm{N}$ se documentaron restos de pinturas murales datadas en época de Trajano-Adriano. El zócalo estaría constituido por paneles anchos con imitaciones de mármoles (fig. 17) (cipollino, numidicum, pavonazzeto, giallo antico), composición que guarda estrecha relación con zócalos de las casas del sector 5E, 5F y 10D de Ilici, con una cronología que va desde mediados del s. I d.C. hasta mediados del s. III d.C. El enorme parecido de las

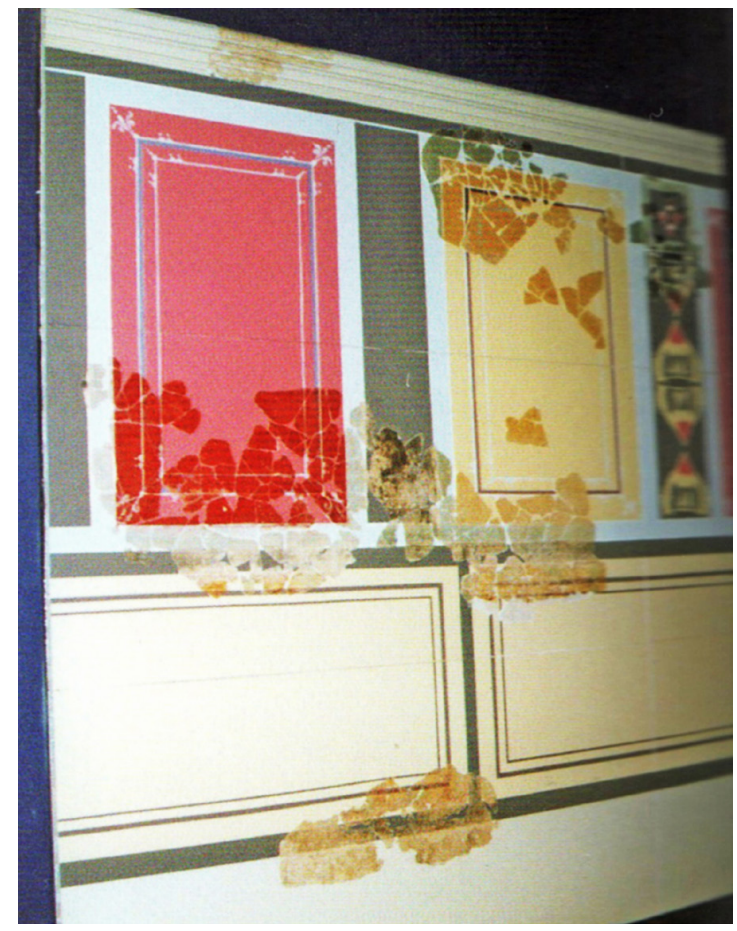

Fig. 17. Reconstrucción de las pinturas de la estancia N expuesta en el MARQ. Lucentum (Tossal de Manises, Alacant) (Olcina 2009). 
decoraciones contribuye a la hipótesis de la existencia de un posible taller itinerante en esta área. La zona media está constituida por paneles coloridos divididos por interpaneles estrechos en negro. El techo se realiza con un sistema de red en el que se insertan diferentes elementos decorativos que resaltan sobre el fondo, elementos vegetales como flores o guirnaldas y elementos figurados como máscaras lunares y pájaros, situados en el interior de círculos (medallones) (Fernández 2000-2001: 218-231).

\section{ILICI}

Los ejemplos de arquitectura doméstica registrados en Ilici, se encuadran dentro del tipo genérico de domus, al tratarse de amplias viviendas familiares con fuentes y jardines en torno a los cuales se distribuyen las dependencias principales: triclinium, tablinum, cubicula, cocina y almacenes. Este tipo de arquitectura muestra un programa constructivo con unas estancias ceñidas a una tipología marcada por su decoración. En este caso las grandes domus se construyeron en sectores periféricos de la ciudad por la escasez de espacio en la zona central, creando barrios señoriales, y pervivieron desde s. I d.C. hasta principios del s. V d.C., con una remodelación realizada en la segunda mitad del s. III d.C. En estas casas el peristilo sirve como fuente de iluminación y ventilación del resto de las dependencias. En estos espacios, el agua cobra vital importancia, presente tanto en los impluvia como en sistemas de abastecimiento y de evacuación por medio de conducciones y de desagües respectivamente.

La ornamentación mural in situ ha permitido establecer su pertenencia a dos etapas, desde los años 50 a 150 d.C. y desde el 275 a 350 d.C., lo que supone que la mayoría de las pinturas pertenecen al segundo periodo debido a la rehabilitación de las mismas, mientras que los pavimentos son altoimperiales.

De los distintos sectores identificados como residenciales destaca el sector $3 \mathrm{~F}$ con una puerta de entrada que conduce al impluvium, rodeado por un peristilo de 16 columnas que comunica con otras estancias y con el jardín, el aljibe conectado con una canaleta al impluvium y a un estanque interior; finalmente, al fondo de la casa se hallan los almacenes (fig. 18) (Ramos 1991: 72-73).

La domus del sector $5 \mathrm{~F}$ fue edificada a finales del s. I d.C. y rehabilitada en el s. III d.C., perdurando hasta principios del s. V d.C. En ella se han identificado diversos ambientes correspondientes a los espacios públicos y privados característicos de las domus romanas. Han aparecido varias estancias que se identifican con cubicula o estancias

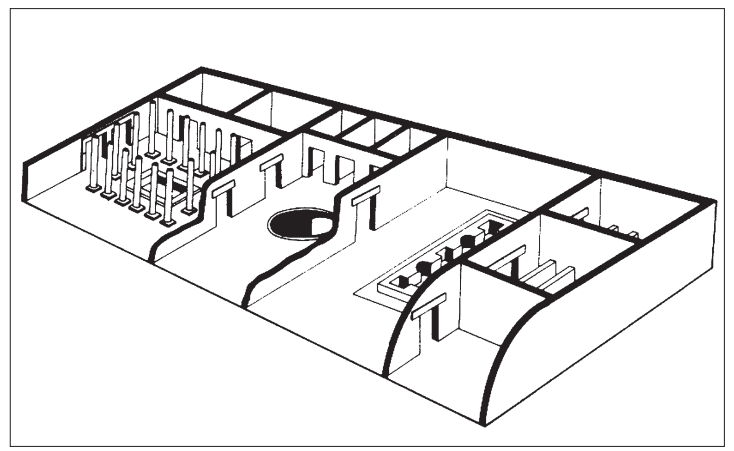

Fig. 18. Reconstrucción de la domus del sector 3F de Ilici. L'Alcúdia, Elx (Ramos 1991).

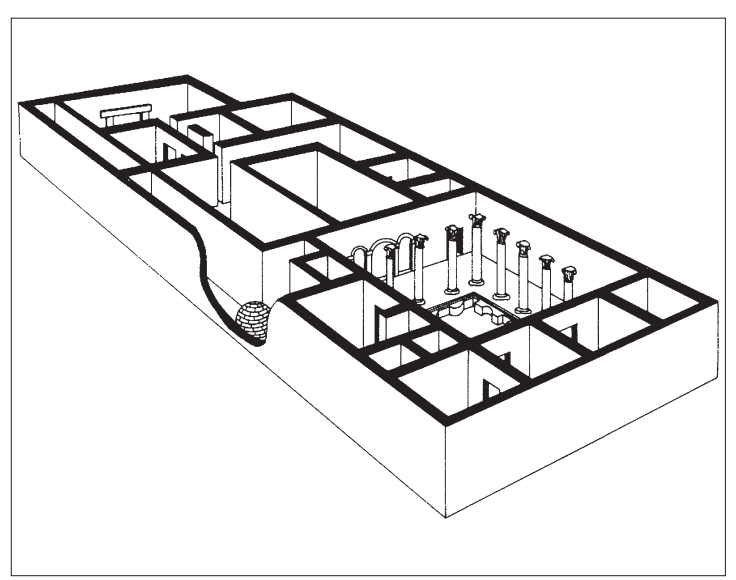

Fig. 19. Reconstrucción de la domus del sector 5F de Ilici. L'Alcúdia, Elx (Ramos 1991).

de reposo, ya que casi todas ellas presentan la decoración propia de estas habitaciones. Una vez dentro de la domus se pasaba de un vestíbulo a un atrio columnado, que aparece conectado con el triclinium a través de tres arcos con dovelas, y que presenta un pavimento en mosaico blanco y una excelente decoración parietal. Precisamente, el diseño de su pavimento hizo posible la identificación de la estancia como triclinium (fig. 19) (Sarabia y Cañavate 2009: 106).

El patio porticado contiene un estanque polilobulado de $49 \mathrm{~m}^{2}$, cuyo interior presenta casetones y semicilindros entrantes y salientes. Rodeado de columnas corintias polícromas, donde se han encontrado marcas de rieles que podrían indicarnos la existencia de una balaustrada que rodearía el estanque (Ramos 1991: 76). La habitación que constituiría el tablinum, reformado 
durante la consolidación de la domus para darle una apariencia más monumental (Sarabia y Cañavate 2009: 106).

El eje de servicio agrupa la cocina, el baño y las letrinas, que de acuerdo con la lógica arquitectónica, se agrupan en la parte más próxima a los conductos de agua y calefacción; de hecho, en una de las paredes del baño y letrinas, se recuperaron restos de una tubería de plomo. Aunque este tipo de decoración es más propia de estancias de representación, las estancias correspondientes al baño contaban con una rica ornamentación tanto pavimental como parietal con temas vegetales y presumiblemente humanos por la aparición de un fragmento de una pierna.

\begin{tabular}{|c|c|c|}
\hline DOMUS & CRONOLOGÍA & EVIDENCIAS PARA LA DATACIÓN \\
\hline $\begin{array}{l}\text { Mosaico del sector } \\
5 \mathrm{~F} \text { (Ilici) }\end{array}$ & $\begin{array}{l}\text { Realización en torno al s. } \\
\text { II a.C./I a.C. }\end{array}$ & $\begin{array}{l}\text { Opus signinum, realizado con teselas de cerámica y guijarros. El uso de antropónimos } \\
\text { ibéricos latinizados como muestra del proceso de romanización producido en esta etapa. }\end{array}$ \\
\hline \multirow{2}{*}{$\begin{array}{l}\text { Domus del Palau } \\
\text { de Benicarló } \\
\text { (Valentia) }\end{array}$} & \multirow{2}{*}{$\begin{array}{l}\text { Primera fase s. II a.C.- } \\
\text { abandono en la primera } \\
\text { mitad s. I a.C. }\end{array}$} & $\begin{array}{l}\text { Primera fase constructiva: Materiales cerámicos como cerámica de barniz negro, sobre } \\
\text { todo Campaniense A. }\end{array}$ \\
\hline & & $\begin{array}{l}\text { Nivel de abandono: incendio documentado con adobes quemados tegulae, dolia y } \\
\text { abundante material cerámico. }\end{array}$ \\
\hline Domus de Lesera & $\begin{array}{l}\text { Finales del s. I a.C.- } \\
\text { mediados del s. II d.C. }\end{array}$ & $\begin{array}{l}\text { Programa ornamental propio de época imperial. Rasgos arquitectónicos que van desde de } \\
\text { una primera fase con elementos ibéricos, hasta una tercera con rasgos inequívocamente } \\
\text { romanos. Las cerámicas más modernas son unos fragmentos de Sigillata hispánica y } \\
\text { africana A, lo que indicaría que la casa fue abandonada a mediados del s. II d.C. }\end{array}$ \\
\hline $\begin{array}{l}\text { Domus dels } \\
\text { Peixos } \\
\text { (Saguntum) }\end{array}$ & $\begin{array}{l}\text { Inicio de la ocupación s. } \\
\text { II d.C., remodelación en } \\
\text { el s. III d.C., abandono s. } \\
\text { IV d.C. }\end{array}$ & $\begin{array}{l}\text { Análisis de los materiales y las superposiciones. Producción africana; cerámica de cocina, } \\
\text { cazuelas formas Ostia III y Lamb 10A-Hayes } 23 \text { B y platos tapadera Ostia I; Terra } \\
\text { sigillata africana A, con platos Lamb 9A- Hayes } 27 \text { y copas Hayes } 14 \text { C; Terra sigillata } \\
\text { hispánica, copas Drag. } 37 \text {, Drag. 27, Drag. } 24 / 25 \text { y el plato Drag. } 18 \text {. Estudio de los } \\
\text { estilos ornamentales. }\end{array}$ \\
\hline \multirow{2}{*}{$\begin{array}{l}\text { Domus de la } \\
\text { Morería Vella } \\
\text { (Saguntum) }\end{array}$} & \multirow{2}{*}{ S. III d.C- s. IV d.C. } & $\begin{array}{l}\text { Arrasamiento y remodelación de estructuras anteriores a la fecha de inicio de la } \\
\text { ocupación. }\end{array}$ \\
\hline & & Análisis de los restos cerámicos y numismáticos de época bajoimperial. \\
\hline $\begin{array}{l}\text { Casa del Mosaico } \\
\text { de los trabajos de } \\
\text { Hércules (Edeta) }\end{array}$ & En torno al s. II d.C. & $\begin{array}{l}\text { Ausencia de documentación al respecto de la datación. Se han documentado tegulae e } \\
\text { imbrices con pequeños fragmentos cerámicos correspondientes a mediados del s. II d.C. } \\
\text { en la balsa de agua aparecida en Pla de L'Arc relacionada con la domus de Hércules, lo } \\
\text { que podría aportar datos sobre la cronología. }\end{array}$ \\
\hline $\begin{array}{l}\text { Casa del Tesoro } \\
\text { (Edeta) }\end{array}$ & $\begin{array}{l}\text { Segunda mitad del s. I } \\
\text { d.C.- abandonada en } \\
\text { torno al } 270 \text { d.C. }\end{array}$ & $\begin{array}{l}\text { Estudio numismático de las acuñaciones del tesoro (desde Nerón hasta Clodio Albino y } \\
\text { Septimio Severo), la fecha de ocultación es el } 193 \text { d.C. Por las reformas del atrium } \\
\text { sabemos que se abandonaría más tarde. }\end{array}$ \\
\hline $\begin{array}{l}\text { Domus de } \\
\text { Terpsícore } \\
\text { ( Valentia) }\end{array}$ & $\begin{array}{l}\text { Inicio de la ocupación s. } \\
\text { I d.C, remodelación en el } \\
\text { s. II d.C. }\end{array}$ & $\begin{array}{l}\text { Sala del mosaico de Terpsícore adaptada a los gustos estilísticos del s. II d.C. El estudio } \\
\text { de la ornamentación, de los materiales y de las técnicas constructivas confirman la } \\
\text { datación. }\end{array}$ \\
\hline $\begin{array}{l}\text { Domus de la } \\
\text { Almoina }\end{array}$ & $\begin{array}{l}\text { Amortizada a finales del } \\
\text { s. II d.C. o a ppios. del s. } \\
\text { III d.C. }\end{array}$ & $\begin{array}{l}\text { Material cerámico y estratigrafía. El estudio de la ornamentación la sitúa estilísticamente } \\
\text { en el s. II d.C. Del s. III d.C. aparece cerámica sigillata africana, hispánica y un } \\
\text { fragmento de lucerna Deneauve VII A. }\end{array}$ \\
\hline $\begin{array}{l}\text { Domus del } \\
\text { Peristilo } \\
\text { (Lucentum) }\end{array}$ & Época imperial & Ausencia de datos sobre los materiales aparecidos. \\
\hline $\begin{array}{l}\text { Domus de la } \\
\text { Puerta Oriental } \\
\text { (Lucentum) }\end{array}$ & $\begin{array}{l}\text { Desde mediados del s. I } \\
\text { d.C. hasta el último } \\
\text { cuarto del s. II d.C. }\end{array}$ & $\begin{array}{l}\text { Cisterna abandonada en el s. II d.C. Estudio estilítico de las pinturas murales, } \\
\text { pertenecientes al reinado de Trajano y Adriano. }\end{array}$ \\
\hline $\begin{array}{l}\text { Domus del sector } \\
3 \mathrm{~F} \text { (Ilici) }\end{array}$ & $\begin{array}{l}\text { Edificada a finales del s. } \\
\text { I d.C., remodelada en el } \\
\text { s. III d.C., abandonada } \\
\text { en el s. V d.C. }\end{array}$ & $\begin{array}{l}\text { Los estudios de la ornamentación mural in situ marcan dos etapas: desde los años } 50 \text { a } \\
150 \text { d.C propia de la construcción de la domus y otra desde el } 275 \text { al } 350 \text { d.C momento } \\
\text { de la rehabilitación. }\end{array}$ \\
\hline $\begin{array}{l}\text { Domus del sector } \\
5 \mathrm{~F} \text { (Ilici) }\end{array}$ & $\begin{array}{l}\text { Edificada a finales del s. } \\
\text { I d.C., rehabilitada en el } \\
\text { s. III d.C., abandonada } \\
\text { en el s. V d.C. }\end{array}$ & $\begin{array}{l}\text { Los estudios de la ornamentación mural in situ marcan dos etapas: desde los años } 50 \text { a } \\
150 \text { d.C propia de la construcción de la domus y otra desde el } 275 \text { al } 350 \text { d.C momento } \\
\text { de la rehabilitación. }\end{array}$ \\
\hline
\end{tabular}

Fig. 20. Cuadro resumen. 
Si analizamos la vivienda desde su accesibilidad comprobamos que se trata de un esquema complejo, con un primer espacio de articulación en el vestíbulo y un segundo en el peristilo centralizando el ingreso a las estancias de mayor representatividad. Del mismo modo los recientes análisis de isovistas corroboran un primer punto de visibilidad en el eje de entrada y otro en el peristilo, con una perspectiva visual marcada por la axialidad que genera la alineación del patio con las salas interpretadas como triclinium y tablinum (Sarabia 2013: 81).

Dentro de la infraestructura hidráulica de la domus destacan unos subterráneos que recorren la casa de $\mathrm{N} \mathrm{a} \mathrm{S}$ y que servirían de cloaca para desaguar al río. En un primer momento se identificaron como galerías de escape, para utilizar en caso de peligro pero, actualmente, se han documentado tramos de alcantarillado de la red urbana similares a éste (Ramos 1991: 76).

Los programas decorativos hallados en Ilici revelan cómo se desarrolló en toda la costa la misma influencia decorativa, donde se traspusieron los mismos cartones decorativos, musivos y pictóricos, con grandes similitudes entre ellos, lo que nos lleva a deducir la existencia de un taller de artesanos itálicos, instalado en una u otra ciudad cercana, desde el que se difundieron los temas compositivos y repertorios ornamentales (Fernández 2004: 167-168).

\section{CONCLUSIONES}

La primera conclusión que cabe extraer de esta exposición sintética de los restos más representativos de la arquitectura doméstica urbana en el territorio valenciano, concierne a la acusada desproporción existente entre los datos referidos a la época republicana, que son muy escasos, frente a un mayor volumen correspondiente a la época imperial. Esta evidente desigualdad de información se justifica desde dos factores, por una parte, las huellas en forma de destrucciones que dejaron los conflictos que sacudieron a Roma a finales del período republicano, y que en el territorio valenciano fueron especialmente virulentos. Por otra parte, la circunstancia de que muchas construcciones de época imperial romana se edificaron sobre los restos de estructuras republicanas precedentes. Ello otorga mayor importancia a los contados exponentes de época republicana, como el mosaico de L'Alcúdia (Elx) con nombres ibéricos en grafía latina y los restos documentados en el Palau de Benicarló de València.
Tanto las plantas en su conjunto, como la disposición interna de los diferentes espacios domésticos, denotan grados diferentes de adopción de modelos itálicos con un protagonismo muy destacado para elementos como el atrio o el peristilo a la hora de articular dicha distribución espacial interna. Hay ejemplos muy evidentes de adecuación al esquema de eje axial, como la denominada Domus dels Peixos en Saguntum y la casa con representación pictórica de Mercurio en Valentia. Otros exponentes, como la Domus 5F de Ilici y la denominada Domus de Terpsícore en Valentia, muestran la importancia de los peristilos dotados de pórticos.

Otra importante conclusión atañe a la importancia de los programas decorativos como reflejo del status social, económico y cultural de quienes detentaron la propiedad de los inmuebles. En el caso concreto de la denominada Domus de Terpsícore en Valentia, el carácter excepcional de alguna de sus decoraciones, unido a otras consideraciones, ha llevado en recientes trabajos a cuestionar su carácter privado. Particularmente interesantes resultan las estrechas similitudes de determinadas decoraciones en los casos de Lucentum e Ilici, que pueden estar indicando la existencia de un taller itinerante que prestaría servicio a ciudades cercanas .

Con la excepción de ciudades como Lucentum, donde su abandono se documenta a finales del s. II d.C. o la Casa del Tesoro de Edeta, abandonada en el 260-270 d.C., un buen número de viviendas registraron importantes reformas en el s. III d.C., como se constata en Saguntum, Valentia e Ilici, perdurando hasta su abandono que se produjo en algunos casos, en el s. IV d.C., mientras que en Ilici se llevó a efecto en el s. V d.C. (fig. 20).

Tamara Peñalver Carrascosa Becaria predoctoral Programa FPU del Ministerio de Educación, Cultura y Deporte (convocatoria 18/11/2013) Dept. de Prehistòria i Arqueologia Universitat de València tamara.penalver@uv.es

\section{AGRADECIMIENTOS}

Este artículo es un resumen del trabajo de final del Máster en Arqueología impartido por la Universitat de València, dirigido por el profesor José Luis Jiménez Salvador, al cual quiero agradecer sinceramente todo su apoyo y sus consejos. 


\section{BIBLIOGRAFÍA}

ABAD, L. (1989): El mosaico romano en el País Valenciano: los mosaicos de opus signinum, Mosaicos Romanos, Actas de la I Mesa Redonda Hispano-Francesa sobre Mosaicos Romanos (Madrid 1985), Madrid, 159-167.

ALBIACH, R.; SORIANO, R. (1991): Actividades productivas y domésticas en una casa de Valentia, La casa urbana hispanorromana: ponencias y comunicaciones, Institución Fernando el Católico, Zaragoza, 57- 60.

ANTONI, C.; HERNÁNDEZ, F.; DE ANTONIO, J. M. (2006): Noticia preliminar de les excavacions de la domus romana del solar del cinema Marvi (Sagunt), Arse 36, 99-116.

ARASA, F. (2000): L'oscillum d'Edeta, SAGVNTVM.-PLAV 32, 143-150.

ARASA, F. (2009): La ciutat romana de Lesera, Ajuntament de Forcall, 62-73.

BALIL, A. (1971): Casa y urbanismo en la España antigua, $B S A A$ 37, 311-328

BALIL, A. (1972): Casa y urbanismo en la España antigua, $B S A A$ $38,55-131$

BALIL, A. (1973): Casa y urbanismo en la España antigua, BSAA 39, 115-188

BALIL, A. (1977): Mosaico con representación de los trabajos de Hércules hallado en Cartama, BSAA 43, 371-379

BALIL, A. (1978): El mosaico de 'Los trabajos de Hércules', APL $\mathrm{XV}, 265-275$.

BELTRÁN, M. (2003): La casa hispanorromana. Modelos, Bolskan 20, 13-63

BURRIEL, J. M.; RIBERA, A.; SERRANO, M. L. (2004): Un área portuaria romana al norte de Valentia, Puertos fluviales antiguos: ciudad, desarrollo e infraestructuras (Valencia, 2003) (G. Pascual, J. Pérez Ballester, eds.), Valencia, 127-142.

CALVO, M.; MARÍN, C.; MARTÍNEZ, R.; MATAMOROS, C. (1998): De Valentia a Les Corts, Valencia.

CHINER, P.; LÓPEZ, M. (1994): Noticia preliminar de las excavaciones de la Domus tardía del solar del Romeu (Sagunto), SAGVNTVM-PLAV 27, 229-237

CORELL, J. (1999): Inscripcions romanes d'Ilici, Lucentum, Allon, Dianium i els seus respectius territoris, Valencia, 78-79.

CORELL, J. (2009): Inscripcions romanes de Valentia i el seu territori, Valencia.

DE HOZ, M. P. (2007): A new set of simulacra gentium identified by greek inscription in the so-called "House of Terpsichore" in Valentia (Spain), Zeitschrift für Papyrologie und Epigraphik, 159, 131-148.

DELEGIDO, C. (2011): El tesoro de Llíria, XIV Congreso Nacional de Numismática, Madrid, 677-694.

ESCRIVÀ, V.; MARTÍNEZ, C.; VIDAL, X. (2001): Edeta kai Leiria. La ciudad d'Edeta de l'època romana a l'antiguitat tardana, Lauro: Quaderns d'Historia i Societat 9, 66-74.

ESCRIVÀ, M. I.; JIMÉNEZ, J. L.; MACHANCOSES, M.; RIBERA, A. (e. p.): Una nueva interpretación como posible edificio público para la denominada Domus de Terpsícore en Valentia, Los espacios de reunión de las asociaciones romanas. Diálogos desde la arqueología y la historia, en homenaje a Bertrand Goffaux, Casa de Velázquez, Madrid.

FERNÁNDEZ, A. (2000-2001): Algunos restos pictóricos de la ciudad de Lucentum (Tossal de Manises-Alicante), Lucentum 19-20, 215-236.

FERNÁNDEZ, A. (2004): Los programas ornamentales, pintura y mosaico, Iberia, Hispania, Spania, una mirada desde Ilici, Caja de Ahorros del Mediterráneo, Alicante, 167-174.

FERNÁNDEZ,A. (2007a): La pintura romana valenciana y sus modelos pompeyanos, Pompeya bajo Pompeya. Las excavaciones en la casa de Ariadna (A. Ribera, M. Olcina, C. Ballester, eds.), Valencia, 143-146.

FERNÁNDEZ, A. (2007b): Un nuevo ejemplo de personificación de provincia romana en la decoración pictórica de la Domus de Terpsícore (Valencia). Un tema iconográfico propio de mediados del s. II d.C, Circulación de temas y sistemas decorativos en la pintura mural antigua (C. Guiral ed.), Zaragoza, 461-466.

GÓMEZ PALLARÉS, J. (1997): Edición y comentario de las inscripciones sobre mosaico de Hispania. Inscripciones no cristianas, Roma, 38-39.

GOZALBES, M.; RIPOLLÈS, P. P.; ESCRIVÀ, V.; VIDAL, X. (2005): El tesoro de denarios imperiales de Llíria III (Valencia), Actas del XIII Congreso Internacional de Numismática, (Madrid 2003) (C. Alfaro, C. Marcos, P. Otero, coords.), Vol. 1, Madrid, 691-696.

GUIRAL, C. (2000): La pintura romana en España: aportaciones recientes, La pintura romana antigua (T. Nogales, ed.), Actas del Coloquio Internacional (Mérida 1996), Mérida, 21-35.

JIMÉNEZ, J. L. (1999): ¿Mercurio o Hipnos? Un ejemplo de ambigüedad iconográfica en una pintura mural romana procedente de Valencia, AAC 10, 201-216.

JIMÉNEZ, J. L. (2007): El reflejo pompeyano de la casa romana en las tierras valencianas, Pompeya bajo Pompeya. Las excavaciones de la Casa de Ariadna (A. Ribera, M. Olcina, C. Ballester, eds.), Valencia, 140-142.

JIMÉNEZ, J. L.; RUIZ, E.; BURRIEL, J. M. (2007): La intervención arqueológica, Palau de Cerveró, Universitat de València, 99-252.

KROUGLY, L.; MARÍN, C.; MATAMOROS, C.; MONRAVAL, M.; RIPOLLÈS, E. (1997): La domus de Terpsícore (Valencia, España), I temi figurativi nella pittura parietale antica (IV sec. a C.-IV sec.d.C.) (D. Scagliarini, coord.), Atti del VI Convegno Internazionale sulla Pittura Parietale Antica (Bologna, 1995), Imola, 225-228.

LÓPEZ, I.; MARÍN, C.; MARTÍNEZ, R.; MATAMOROS, C. (1994): Hallazgos arqueológicos en el Palau de les Corts, Corts Valencianes, Valencia.

MARÍN, C.; MATAMOROS, C.; RIBERA, A. (1991): Restos de una vivienda de época tardo-republicana (s. II-I a.J.C.) en Valentia: Los hallazgos del Palau de les Corts Valencianes, 
La casa urbana hispanorromana: ponencias y comunicaciones (Zaragoza, 1989), Institución Fernando el Católico, Zaragoza, 61-66

MARÍN, C.; MATAMOROS, C. (1994): Época romana. Desde sus orígenes en la época republicana a la antigüedad tardía, Hallazgos arqueológicos en el Palau de les Corts (I. López, C. Marín, R. Martínez, C. Matamoros, coords.), Corts Valencianes, Valencia, 39-178.

MELCHOR, J. M; BENEDITO, J. (2005): La excavación del solar de la Plaça de la Moreria Vella (Sagunto, Valencia) y la Saguntum romana, Arse 39, 11-34.

MONTESINOS, J.; BUCHÓN, A. (2011): Arte Antiguo, Llíria, historia, geografía y arte, Nuestro pasado y presente, Universitat de València, 149- 177.

MOSTALAC, A.; BELTRÁN, M. (1988): La pintura romana como fuente de conocimiento en la escultura antigua. La influencia de la obra de Lisipo en el ciclo de los trabajos de Hércules de la Colonia Lepida-Celsa, II Reunión sobre escultura romana en Hispania, Tarragona, 239-260.
OLCINA, M. (2009): LUCENTUM (Tossal de Manises, Alicante) Arqueología e Historia, MARQ, Museo Arqueológico de Alicante, 104-114.

RAMOS, R. (1991): La casa urbana hispanorromana en Illici, La casa urbana hispanorromana, ponencias y comunicaciones, Institución Fernando el Católico, Zaragoza, 69-78.

ROSSELLÓ, M.; SORIANO, R.; (1998): Los restos arqueológicos exhibidos, Cripta arqueológica de la Cárcel de San Vicente, Ajuntament de València, 41-56.

SARABIA, J. (2013): La casa romana como espacio de conciliación entre el ámbito doméstico y la representación socioeconómica del dominus: Algunos casos de estudio del Conventus carthaginiensis, De la estructura doméstica al espacio social. lecturas arqueológicas del uso social del espacio (S. Gutiérrez, I. Grau, eds.), Universidad de Alicante, 169-188.

SARABIA, J.; CAÑAVATE, V. (2009): La arquitectura doméstica romana en la Alcudia de Elche. La domus 5-F, Lucentum $28,89-110$. 